\title{
AS ÁGUAS SUBTERRÂNEAS NA GESTÃO DOS RECURSOS HÍDRICOS NA BACIA HIDROGRÁFICA DO RIO CURU - CE
}

\author{
Filipe da Silva Peixoto, Renata Nayara CÂmara Miranda Silveira, \\ Itabaraci Nazareno Cavalcante, Diego TeiXeira de Araújo, Rafael Mota de Oliveira
}

Universidade Federal do Ceará (UFC)

<fpeixoto10ufc@gmail.com>, <renayarac@gmail.com><itabaracicavalcante@gmail.com> <diegogeoufc@gmail.com>.<rafaelmota20@yahoo.com.br>

DOI: 10.21439/conexoes.v11i1.1097

\begin{abstract}
Resumo. A gestão dos recursos hídricos deve promover o uso integrado das águas, sendo necessário, para isso, a utilização de instrumentos legais para promover de forma racional e estratégica a gestão. O presente estudo buscou investigar se as águas subterrâneas possuem inserção na gestão dos recursos hídricos na Bacia Hidrográfica do Rio Curu - CE. Foram identificados os usos, a aplicação de outorgas e a distribuição dos poços outorgados com relação aos sistemas hidrogeológicos. Para isso, foi avaliado o número de poços com outorga e as vazões outorgadas até 2014 através de arquivo de dados disponibilizados pela Companhia de Gestão de Recursos Hídricos do Ceará (COGERH). Foi ainda avaliado a localização geográfica dos poços outorgados nos distintos sistemas hidrogeológicos, que foram baseados no mapa litológico da Companhia de Pesquisa e Recursos Minerais (CPRM). Constata-se uma pequena aplicação do instrumento de outorga nas águas subterrâneas, além de maior volume de água subterrânea em outorga (57\%) está destinado para a atividade de irrigação.
\end{abstract}

Palavras-chaves: Gerenciamento das Águas Subterrâneas. Uso das águas. Outorgas.

\begin{abstract}
The management of water resources should promote integration of actions between groundwater and surface water, if necessary, for this, the use of legal instruments to promote rational and strategic water management. The study sought to investigate the role of groundwater in the Management of Water Resources in River Basin Curu, on use and grant's application, and the granted well's distribution in function of the hydrogeological systems. We evaluate the number and of granted wells outflow from of data of the Water Resource Company (COGERH). To investigate the occurrence and distribution of wells granted with respect to hydrogeological systems based in lithologic map of the Resource Mineral Research Company (CPRM). We evidence a little grant application in groundwater. In addition, it was found that the largest volume of groundwater in grants $(57 \%)$ is intended for irrigation activity.
\end{abstract}

Keywords: Groundwater Management. Water Use. Grant.

\section{INTRODUÇÃO}

A gestão das águas é definida como "o conjunto de procedimentos organizados no sentido de solucionar os problemas referentes ao uso e ao controle dos recursos hídricos" (CAMPOS, 2001). Quantificar a oferta e demanda é uma condição básica para a gestão dos recursos hídricos, sendo, segundo Barth (1987), necessário equacionar questões relacionadas à escassez relativa dos recursos hídricos.

A implementação da gestão dos recursos hídricos no estado do Ceará foi impulsionada pela necessidade de implementação da infraestrutura hídrica para o aumento da oferta e disponibilidade hídrica, tendo em vista a resiliência às constantes secas (CAMPOS, 2015). O modelo de gestão participativo foi criado desde 1992 quando foi instituída a Política Estadual dos Recursos Hídricos - PERH Lei $\mathrm{n}^{\circ} 11.996 / 92$, implementando a bacia hidrográfica como unidade territorial de gestão. Tal fato está ligado à proposição dos princípios da Conferência de Dublin em 1990 e da Rio 92, o que norteou as políticas de recursos hídricos no Brasil até então 
(PORTO; PORTO, 2008). A antiga política de recursos hídricos foi substituída pela atual PERH Lei 14.844/10 com o intuito de se adequar à Política Nacional dos Recursos Hídricos - PNRH, Lei n 9.433/97.

Um dos princípios fundamentais que norteiam as legislações vigentes é a gestão e uso integrado das águas subterrâneas e superficiais no gerenciamento dos recursos hídricos (PNRH, 2006). A oferta hídrica é essencial para a geração das atividades econômicas e sobretudo para as relações bióticas e atendimento das necessidades sociais. Em ambientes que sofrem frequentemente com a escassez hídrica em consequência das irregularidades climáticas é necessário a oferta hídrica para suprir as demandas hídricas para fomentar o desenvolvimento socioeconômico (VIVAS; MAIA, 2010).

A bacia hidrográfca do Rio Curu drena uma área de $8.750,75 \mathrm{~km}^{2}$, equivalente a $6 \%$ do território cearense, na qual apresenta condições peculiares de escassez hídrica e com irregularidades climáticas perculiares do semiárido Cearense. Apresenta uma precipitação média anual de $919 \mathrm{~mm}$, com alta variabilidade espaço-temporal das chuvas, temperatura média anual é de $27^{\circ} \mathrm{C}$, propiciada pelo clima Tropical Quente Semiárido (SANTANA, 2009). Existem dois domínios hidrogeológicos: o das rochas sedimentares (Porosos); e os das rochas cristalinas (Fraturado) (CPRM, 2004).

Os poços construídos em geologia cristalina são mais numerosos por conta de sua grande representatividade regional, contudo, as vazões dos poços construídos na litologia cristalina são menores do que as dos poços presentes na litologia sedimentar. Existiam, até 2006, 1.418 poços cadastrados, sendo que os poços tubulares predominam com $97 \%$ e, desses, $73 \%$ captam água do meio fraturado, desses poços ressalta-se que $42 \%$ apresentam vazões entre a $2 \mathrm{~m}^{3} / \mathrm{h}$ e $3 \mathrm{~m}^{3} / \mathrm{h}$ a maioria apresenta vazões inferiores a essa (SANTANA 2009).

Diante desse contexto problemático e do aumento da demanda hídrica, propôs-se investigar se há inserção das águas subterrâneas no gerenciamento dos recursos hídricos da Bacia Hidrográfica do Rio Curu, de modo a promover a gestão e uso integrado das águas. Além de observar os aspectos de uso relacionado a água subterrâneas assim como a ocorrência de poços com vazões outorgadas de acordo com os domínios hidrogeológicos presentes na área.

\section{MATERIAL E MÉTODOS}

A investigação foi realizada a partir de levantamentos de dados de outorga dos poços localizados na Bacia Hidrográfica do Rio Curu (Figura 1), disponibilizados pela Companhia de Gestão dos Recursos Hídricos
- COGERH. Foi analisado as vazões outorgadas das água subterrânea e a quantidade de poços outorgados até dezembro de 2014. Os dados de vazões de outorgas dos poços e dos sistemas hídricos superficiais consistem no banco de dados de outorgas da COGERH, portanto são dados secundários, refletem inserção desses volumes hídricos no processo de gestão das águas na bacia. Realizou-se ainda uma análise comparativa com os dados de vazões outorgada referentes às águas superficiais, resultando em um balanço de outorgas entre estas.

Foram observados os usos das águas subterrâneas em função das atividades econômicas e sociais presentes na bacia, conforme o direcionamento proposto na concessão da outorga. Elas consistem em: I - abastecimento público; II - dessedentação de animais; III industria; IV - irrigação; V - demais usos.

Para a análise ressalta-se a importância da ferramenta de SIG - Sistema de Informação Geográfica, no que tange a inserção dos dados em ambiente espacial que permitiu a associação das ocorrências dos poços com vazões outorgadas à diversidade geológica da bacia. A ferramenta SIG tem sido utilizada na gestão dos recursos hídricos, conforme Chowdary et al. (2009), Jha, Chowdhury e Chowdary (2007), sendo importante na identificação de atributos locacionais e por isso estratégico para o aumento da oferta e estratégias de preenchimento de vazios hídricos, ou seja, comunidades que não possuem acesso direto ao abastecimento convencional.

\section{RESULTADOS E DISCUSSÕES}

De acordo com dados da COGERH, observou-se que a dimensão do volume de outorga das águas superficiais é de $248,410 \times 106 \mathrm{~m}^{3}$ ano $^{-1}$, enquanto que das águas subterrâneas é de $1,236 \times 106 \mathrm{~m}^{3}$ ano $^{-1}$ (Tabela 1 ).

Os resultados demonstram que o grande volume de águas superficiais outorgado é reflexo da estratégia de gerenciamento através da construção de obras barragistas que viabilizam a oferta hídrica superficial. Consequentemente, o volume de águas subterrâneas outorgado é baixo. Porém, de acordo com (SANTANA. 2009), os poços existentes na bacia do Rio Curu têm uma vazão média de $2,47 \mathrm{~m}^{3} \mathrm{~h}^{-1}$ o que são capazes de beneficiar aproximadamente 33.600 famílias. Oliveira, Luna e Caldas (2014) coloca que o principal desafio dos órgãos gestores na referida bacia é a articulação para o controle dos prejuízos causados pelas secas, sendo que a alocação das águas superficiais é o principal instrumento para a minimização dos impactos negativos.

O grave problema de escassez hídrica e irregularidade de chuvas deve ser contornado com a ajuda de for- 


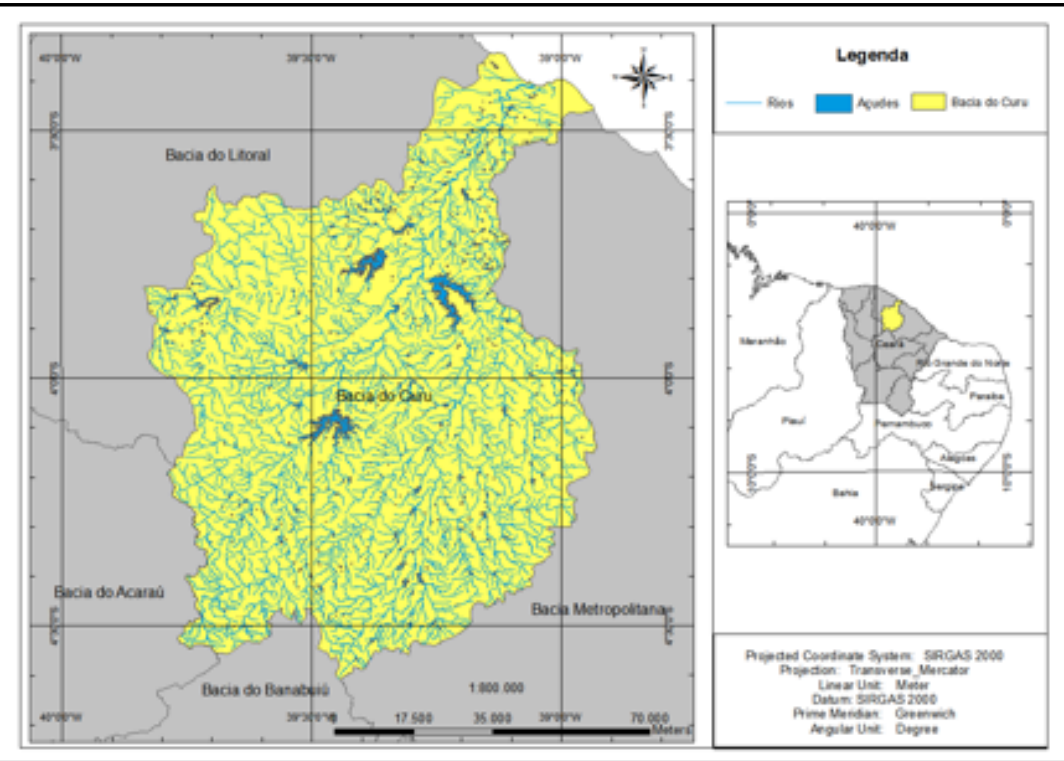

Figura 1: Localização da Bacia Hidrográfica do Rio Curu

Tabela 1: Outorgas: volumes em $\mathrm{m}^{3}$ /ano na Bacia Hidrográfica do Rio Curu, Ceará

\begin{tabular}{lll}
\hline Outorga & Volume $\left(\times 10^{6} \mathrm{~m}^{3} \mathrm{ano}^{-1}\right.$ & Volume $(\%)$ \\
\hline Águas Superficiais & 248,410 & 99,50 \\
Águas Subterrâneas & 1,236 & 0,50 \\
Total & 249,647 & 100 \\
\hline
\end{tabular}

Fonte: COGERH, 2014.

mas alternativas de aumento da oferta hídrica. As águas subterrâneas possuem essa potencialidade, pois se mostram muito menos susceptíveis ao efeito de evapotranspiração que as águas superficiais.

Em relação à quantidade de poços com outorgas, contabilizou-se 29 poços, sendo estes distribuídos de forma irregular, variando em função da ocorrência dos domínios hidrogeológicos, e refletindo suas diferentes vazões caracterizados pelas respectivas propriedades hidrogeológicas referentes a cada sistema.

Observou-se que $51,7 \%$ dos poços estão localizados em áreas de aquíferos intersticiais (Porosos), abrangendo 5,48\% da bacia, nas quais observamos litotipos sedimentares representados pela Formação Barreiras, Depósitos Aluvionares e Depósitos Eólicos Litorâneos. Assim, 48,3\% dos poços estão contidos em litotipos cristalinos, que abrangem 94,52\% da área (Figura 2). Tais tipos de rochas possuem baixa porosidade primária, nesses tipos litológicos a ocorrência de água subterrânea está associada à fraturamentos, falhas, ou ao manto de intemperismo (FETTER, 2001). No entanto, no semiárido nordestino "não se tem condições favo- ráveis à estocagem de água no seu subsolo, protegida dos intensos processos de evaporação" (REBOUÇAS. 2002 p.42).

Observa-se, pela disposição espacial, que a densidade de poços com vazões outorgadas é bem maior próximo ao litoral, onde os litotipos sedimentares são presentes. Enquanto os terrenos cristalinos representam meios hidraulicamente descontínuos, heterogênios e anisotrópicos (SANTOS, 2010, BOUTT; DIGGINS; MABEE, 2010). Por conseguinte, a dificuldade de estudos e locação de poços no cristalino dar-se-á, sobretudo, pela dificuldade de mensurar parâmetros hidrodinâmicos. Assim a disposição difusa e baixa densidade de poços no restante da área ocorre pelas incertezas de produtividade destes, mais também pelas características de ocupação mais rarefeita nessa área da bacia.

Levando-se em consideração o uso da água subterrânea, é tido como princípio, nas legislações federal e estadual, o uso múltiplo, objetivando atender as diferentes demandas sociais. No Art. 15 do Decreto $\mathrm{n}^{\circ}$ 23.067/94 "Dar-se-á prioridade para abastecimento doméstico, em consoante com Legislação Federal Lei $n^{\circ}$ 


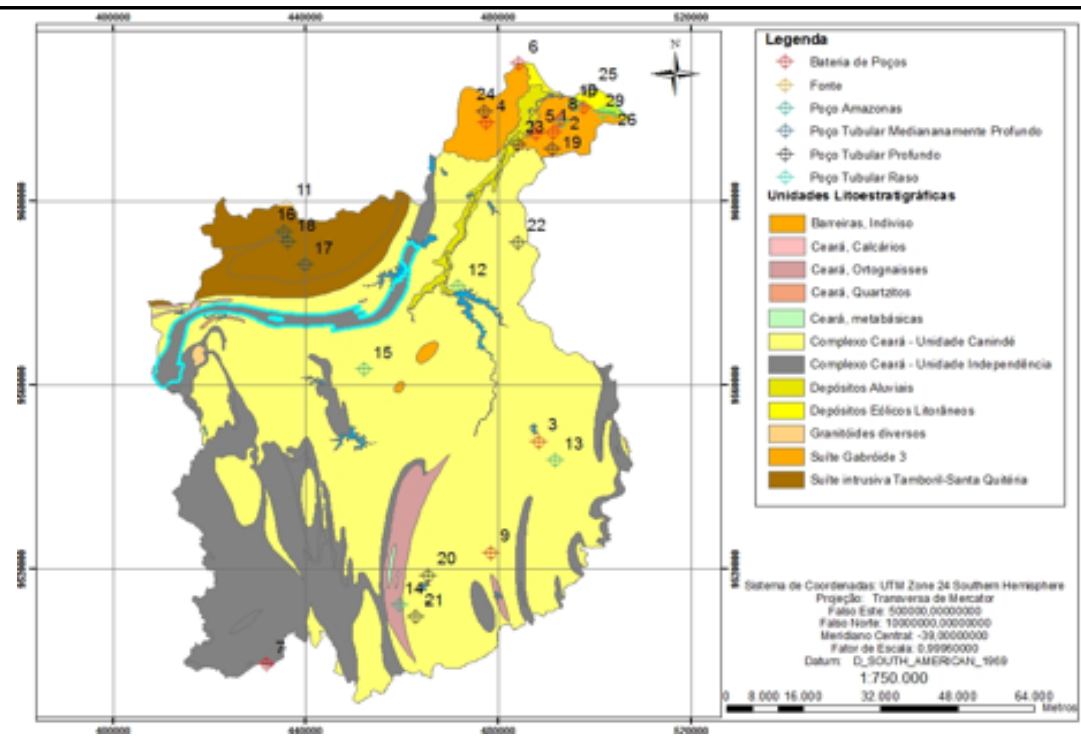

Figura 2: Distribuição dos poços por tipo e litologia

Fonte: Geologia do Ceará - CPRM (2014

\subsection{3/97"}

Posição também reforçada da Lei 14.844/10: “A outorga de direito de uso de recursos hídricos tem por objetivo efetuar o controle do uso e assegurar o direito de acesso à água condicionada às prioridades estabelecidas no Plano Estadual de Recursos Hídricos e nos Planos de Bacias Hidrográficas" (Art. 6, $\S 2^{\circ}$ ). Além do abastecimento doméstico, foi também inserida a dessedentação de animais como prioritários na PERH (2010).

Na Bacia do Rio Curu existem 29 poços outorgados, sendo que, a maioria é utilizado para fins industriais. Cerca de $27 \%$, enquanto que $24 \%$ dos poços são destinados para dessedentação de animais, e somente $21 \%$ para o abastecimento humano (Figura 3).

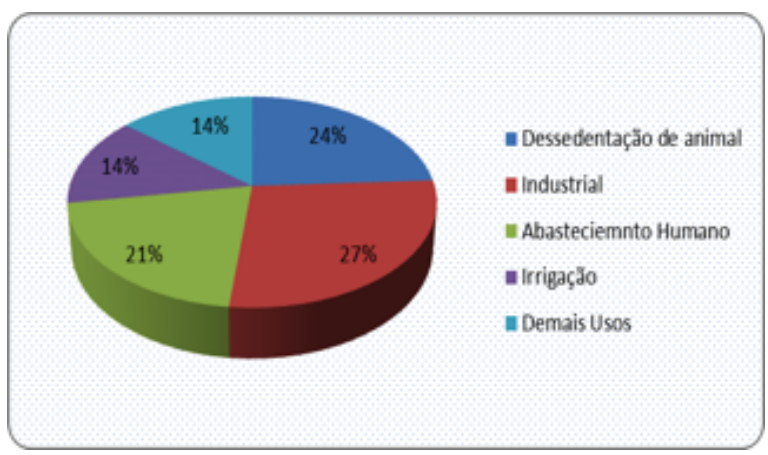

Figura 3: Quantidade percentual dos poços, em relação à destinação de uso

\section{Fonte: COGERH (2014}

A distribuição da média do volume de vazão outor- gada, em litros/hora, com relação aos usos múltiplos, comporta-se de maneira diferente, haja vista que se tem mais de $1.260 \mathrm{~L} / \mathrm{h}$, cerca de $57 \%$ do volume total, destinado para a irrigação, seguidos de $560 \mathrm{~L} / \mathrm{h}$ para abastecimento humano, correspondendo a $25 \%$ do volume total. Já o uso industrial, que abrange a maior quantidade de poços, representa apenas $6 \%$ do volume total, cerca de $120 \mathrm{~L} / \mathrm{h}$ de vazão (Figuras 4 e 5 )

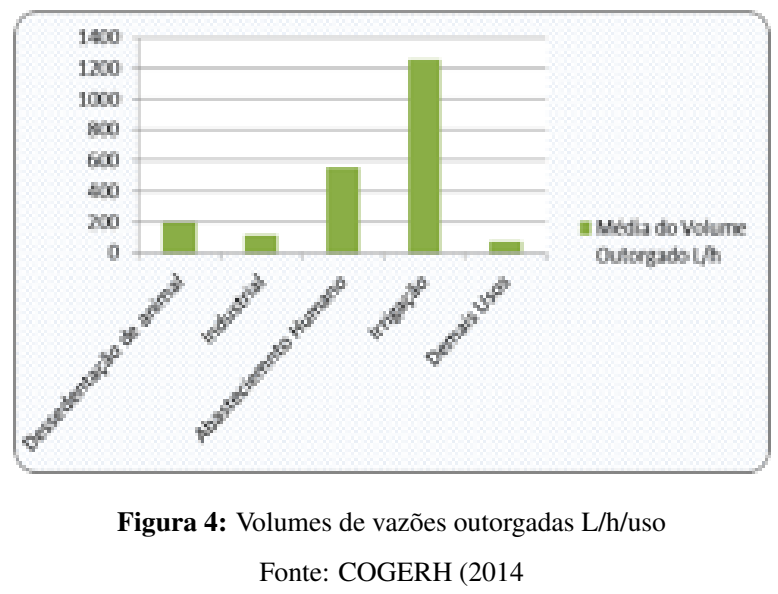

A outorga é um instrumento essencial de gestão, pois possibilita através das concessões desta, o controle qualitativo e quantitativo da água (STUDART, 2002). No Estado do Ceará a outorga é precedida por licença prévia, exigível à execução de acordo com o Decreto $\mathrm{n}^{\circ} 23.068$ de $11 / 02 / 94$, art. $5^{\circ}$. Os poços com melhores vazões são usados na agricultura, no abastecimento 




Figura 5: Vazão de outorgada/uso

humano e na dessedentação de animais. Percebe-se, portanto, uma forte relação da água subterrânea com a atividade agropecuária na bacia, enquanto o abastecimento doméstico se encontra em segundo plano, no que se refere à demanda de água subterrânea outorgada.

No entanto, pode-se presumir que o estudo dos usos da água subterrânea, em outorga, não é de utilidade amostral para uma visão geral dos usos na bacia, considerando o pequeno percentual de volume outorgado da água subterrânea, em relação à água superficial. O uso da água destes podem, também, estar limitados, devido à baixa qualidade das águas. Não se tem dados de qualidades da água subterrânea no sistemas hidrogeológico cristalino dentro da bacia. Contudo avalia-se que a água subterrânea presente na aluvião não apresenta limitações para a agricultura irrigada (SILVEIRA et al. 2015).

A isenção dos poços no processo de outorga da água é um reflexo da não efetividade do gerenciamento das águas subterrâneas. Com o grande número de poços na bacia observa-se a importância destes no abastecimento alternativo em condições de ser direcionado a vários usos. Portanto, a importância da água subterrânea na área é considerável, tanto com relação à quantidade de poços construídos como os múltiplos usos associados a este. Contudo, o prejuízo está, sobretudo, em não atribuir a outorga a grande maioria dos poços, o que contribui para que este recurso continue a margem do gerenciamento hídrico local. Essa realidade está sujeita a medidas emergenciais de perfuração de poços sem critérios de locação nem prioridade de uso (CAVALCANTE; GOMES, 2011).

Todavia, de acordo com os dados disponibilizados pela Companhia de Gestão de Recursos Hídricos do Estado do Ceará (COGERH), em toda a Bacia existiam apenas 29 poços com vazões outorgadas. Constata-se, portanto, que até 2006 cerca de 598 poços deveriam estar com suas respectivas vazões outorgadas. Atual- mente o baixo número de poços, cujas vazões estão outorgadas, não corresponde ao número atual de poços construídos com vazões que exigem outorgas, já que em período de seca é vertiginosa a quantidade de poços construídos, tendendo, portanto, a aumentar.

\section{CONCLUSÕES}

Fica evidente a subutilização do instrumento de outorga nas águas subterrâneas da Bacia do Rio Curu. Atribuise isso à: I - relativas baixas vazões dos poços em virtude das condições hidrogeológicas do embasamento cristalino; II - desconhecimento dos parâmetros hidrogeológicos e dimensionamento de reservas, principalmente no domínio cristalino; III - dificuldade de tomada de decisão e inserção das águas subterrâneas no gerenciamento dos recursos hídricos. Contudo, é necessário um conhecimento dos parâmetros hidrogeológicas para um melhor dimensionamento das potencialidades aquíferas dos aquíferos fissurais e porosos. As águas subterrâneas possuem o potencial de serem utilizadas como reservas estratégicas para períodos de seca prolongados, aumento da oferta hídrica e preenchimento de vazios hídricos, sobretudo em pequenas comunidades, onde é inviável o abastecimento convencional

\section{REFERÊNCIAS}

BARTH, F. T. Fundamentos para a Gestão do Recursos Hídricos. São Paulo: Nobel ABRH, 1987.

BOUTT, D. F.; DIGGINS, P.; MABEE, S. A. Field study (massachusetts, usa) of the factor controlling depth of groundwater flow systems in crystalline fractured-roc terrain. Hydrogeology Journal, v. 18, n. 8 , p. 1839 - 1854, 2010.

CAMPOS, J. N. B. O Modelo Institucional In: Gestão das Águas: Princípios e Práticas. 1 ed. ed. Porto Alegre: Associação Brasileira de Recursos Hídricos, 2001.

Paradigms and public policies drought in northeast brazil: A historical perspective. Environmental Management, n. 55, p. 1052-1053, 2015.

CAVALCANTE, I. N.; GOMES, M. C. R. As águas subterrâneas no Ceará: Ocorrência e Potencialidades. Fortaleza: In: Cleyber Nascimento de Medeiros, C. N; GOMES, D. D. M.ALBUQUERQUE, E. L. S.; CRUZ, M. L. B. (Org's) Os Recursos Hídricos do Ceará: Integração, Gestão e Potencialidades, 2011. 268 p. 
CHOWDARY, V. M.; RAMAKRISHNAN, D.;

SIRIVASTAVA, Y.; CHANDRAN, V.; JEYARAM,

A. Integrated water resource development plan for sustainable management of mayurasshi watershed, india using remote sensing an gis. Water Resource

Management, v. 23, p. 1581 - 1602, 2009.

FETTER, C. Applied Hydrogeology. 4. ed. New Jersey: Prentice Hall, 2001.

JHA, M. K.; CHOWDHURY, A. V. M.; CHOWDARY, S. P. Groundwater management and development by integrated remote sensing and geographic information systems: prospects and constraints. Water Resource Management, v. 21, n. 2, p. 427 - 467, 2007.

OLIVEIRA, M. J. L.; LUNA, R. M.; CALDAS, M. S. Percepção de comitê de bacia sobre a gestão das àguas a bacia hidrográfica do rio Curú, Natal. Natal, p. 35 42, 2014.

PORTO, M. F. A.; PORTO, R. L. L. Gestão de bacias hidrográficas. Estudos Avançados, São Paulo, v. 22, n. 63 , p. $43-60,2008$.

REBOUÇAS, A. A inserção da Água subterrânea no sistema nacional de gerenciamento. Revista Brasileira de Recursos Hídricos, v. 7, n. 4, p. 39-50, 2002.

SANTANA, E. W. Caderno regional da bacia do Curu. INESP, Fortaleza, 2009.

SANTOS, C. B. Avaliação hidrogeológica do alto da Bacia do Rio Jiquiriçá, Estado da Bahia / Salvador. 190 p., Tese (Doutorado em Geologia) - Departamento de geologia, Universidade Federal da Bahia, 2010.

SILVEIRA, R. N. C.; COSTA, R. N. T.; PEIXOTO, F. S.; PINTO, M. P. S. Qualidade do aquífero aluvionar da bacia do rio Curu para fins de irrigação. Quixadá, 2015.

STUDART, T. A. Outorga do direito de uso da água em m cenário de incertezas: o caso do nordeste semiárido. Fundação Konrad Adenauer. Séries Debates, Fortaleza, n. 24, 2002.

VIVAS, E.; MAIA, R. A. Gestão de escassez e secas enquadrando as alterações climáticas. Recursos Hídricos, v. 31, n. 1, 2010. 